\title{
A Design Project that Helps Students to Choose Between Different Fields of Engineering
}

\author{
Rudolf Seethaler \\ University of British Columbia \\ rudolf.seethaler@ubc.ca
}

\begin{abstract}
A new Engineering program has been started in the fall of 2005 at the University of British Columbia, Okanagan Campus. There is a common curriculum for all first and second year students in Civil, Mechanical, and Electrical Engineering. A design project hosted by two separate courses and spanning topics of all three fields of Engineering helps students to decide at the end of their second year, which Engineering program suits them best.
\end{abstract}

\section{Introduction}

At the University of British Columbia, Okanagan Campus, we have the unique situation that Engineering students share a common first and second year. We believe that this leads to a broader knowledgebase of all students. Thus, students make a more informed decision on which engineering discipline to follow as a career path. In our case, students can choose between Civil, Mechanical or Electrical Engineering.

However, before the students reach this decision, they are subjected to a design project where multiple disciplines interact with each other. The students are required to integrate their knowledge bases from different engineering fields and they can experience which field suits them best.

As with all student projects, participation of all team members can only be ensured if the project has enough scope to force the students to share the work load.

\section{UBC $O$ curriculum}

In 2005 a new Engineering program was started at Okanagan Campus of the University of British Columbia. The curriculum is being developed putting special emphasis on design in an integrated learning environment [1]. This is reflected in the first year Engineering Fundamental course (APSC170) that introduces all students to topics such as project management, quality control, and engineering ethics.
Strong emphasis is also put on Engineering Communications. All students are required to take Courses in First Year (APSC176) and second year (APSC201) to improve their writing and presentation skills.

Traditionally, students struggle to understand how the vast amount of engineering material taught in many different engineering courses is linked together. This is addressed by combining many of the traditional three credit courses into six credit courses. For example, Statics, Dynamics, and Algebra are taught in a single course (APSC174) in first year. This allows the instructor to pick vector algebra problems directly related to the other two course components.

One of the largest differences to other engineering schools in Canada is the fact that UBC O offers a common first and second year to students from Civil, Mechanical and Electrical Engineering. Consequently, all students are subjected to a slightly wider knowledgebase across all fields of engineering. This is in response to requests from local industry representatives who were concerned that many graduates are too specialized.

Before entering third year, students are required to choose one of the three offered engineering programs. The school of engineering attempted to help wit this decision by introducing an interdisciplinary design project. Such design projects are becoming more common in many engineering schools [2]. They aim to stress collaborative, as students work in teams on all tasks. Learning is shifted from instructor centered to student centered by defining project goals with a large solution space and only general directions from the instructors. Students also learn that much of the design process consists of thorough analysis, testing, redesign, and documentation.

\section{Project overview}

For the students in the spring of 2006, a hovercraft design was chosen. The goal of the design was to transport a maximum cargo in the least amount of 
time. This was measured in a competition, where the hovercrafts carried pennies across a gymnasium floor. In this project, mechanical engineering was represented by the requirement to optimize lift, thrust, and stability. Civil Engineering was represented by the design of a minimum weight structure. Finally, electrical engineering came into place when deciding on a power management strategy.

The project was part of two different courses: Engineering Materials and Solid Mechanics (APSC251) provided background and laboratory hours to work on the structural components of the project. Fluid Mechanics I (APSC253 ) introduced the material related to fluid mechanics and provided laboratory hours for thrust and lift experiments.

\section{Design process}

The design was scheduled to be completed within a single term. Thus, the students were provided with a set of building materials that included among other things four motors and fans, three planks of Balsa wood, and a Two Channel RC system to control rudder and motor speed. The global design parameters thus reduced to:

- Design for maximum Lift or maximum speed

- Number of motors to be used for lift or drag

- $\quad$ Size and shape of the craft

All teams needed to follow a strict design process that aims to achieve an optimum design. The design process was grouped into four stages. In the first stage, students performed experiments to characterize the components. These experiments were performed as a part of the standard fluid and solid mechanics courses.

In the second stage, students created a simulation that predicted lift speed, and structural strength of their respective crafts. This simulation was used to optimize the craft's size, shape, and the ratio of lift to thrust fans. The simulations were based on algorithms that the students had learned in a previous numerical methods course (APSC256) and they were allowed to use a programming language of their choice to implement their code.

In the third stage, the crafts were assembled and some preliminary tests were carried out in order to ensure that the craft would perform to specs.

Finally, the crafts competed in a public competition that involved judges from industry and academia.

The design process was documented using log books and project reports at the end of each milestone. The results of the simulations were incorporated in the design report. The simulation code was handed in on a CD. The students were encouraged to use CAD programs in order to generate design drawings and predict the amount of material required for their design. Since SolidWorks [3] had been introduced to them in a previous design course (APSC170), it was the program of choice for most groups.

\section{Milestone I: Experiments}

In this step, the students need to characterize the structural strength of the building materials, as well as the lift and thrust of the fans.

The challenge in designing experiments for such a project is to keep the experimental setups simple, while still providing enough data to feed the simulations. We believe that we found a good compromise.

\subsection{Structural experiments}

The design process itself started of with characterizing the balsa wood. Emphasis was placed on the fact that balsa wood differs from the materials that were presented in their first solid mechanics course. Balsa is non homogeneous and the fiber direction plays a mayor role in the design. Also, there is considerable variation in the material properties. Thus, a large enough number of samples need to be tested and a conservative safety factor is essential.

These concepts were validated in three point bending tests. Deflection measurements were used to derive the Young's modulus. The ultimate strength of the material was determined by determining the breaking load for a series of ten samples (see Figure 1).

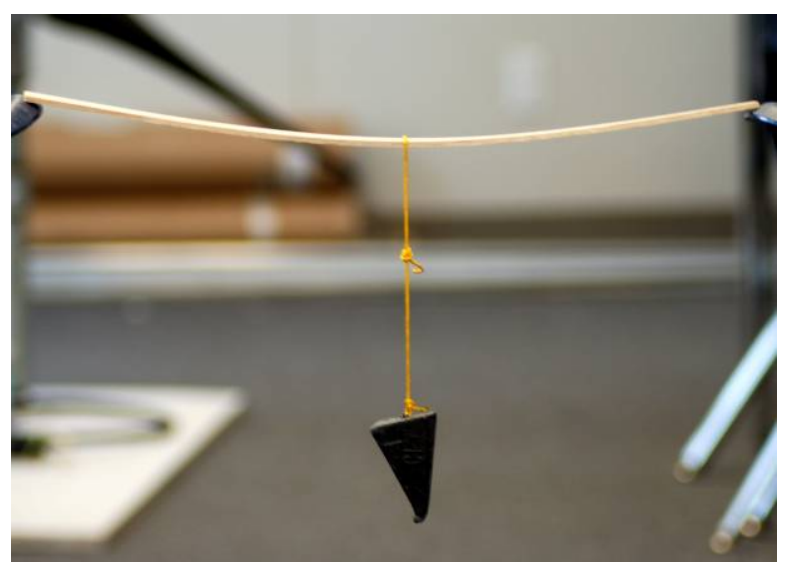

Figure1: Three point bending tests

The gathered information was compared with a data base from ProBalsa[4] and a good correlation was found. 


\subsection{Fluid mechanics experiments}

Four motors were provided that could be used either for lift or for drag. Two sets of experiments were carried out to find the best ratio of lift to drag fans. The same experiments provided the modeling parameters for optimizing size and shape of the crafts. In the lift experiment, the pressure distribution underneath a fan mounted to a Styrofoam plate was measured (see figure 2). The Styrofoam plate could be set at different heights in order to simulate varying air gaps.

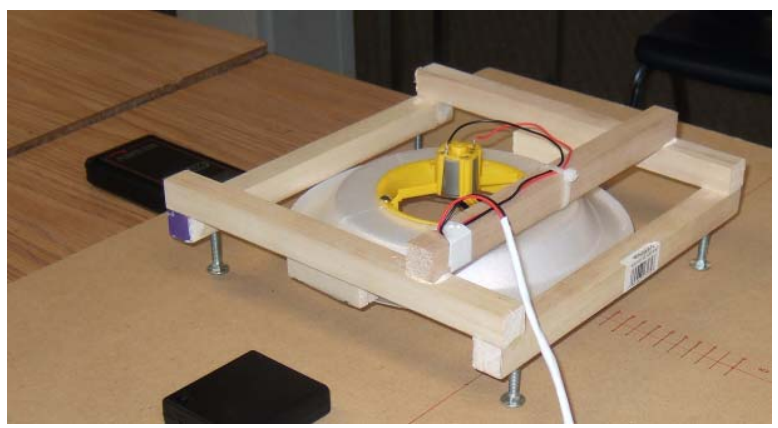

Figure 2: Lift experiment setup

Figure 3 shows typical pressure distributions for three different air gaps.

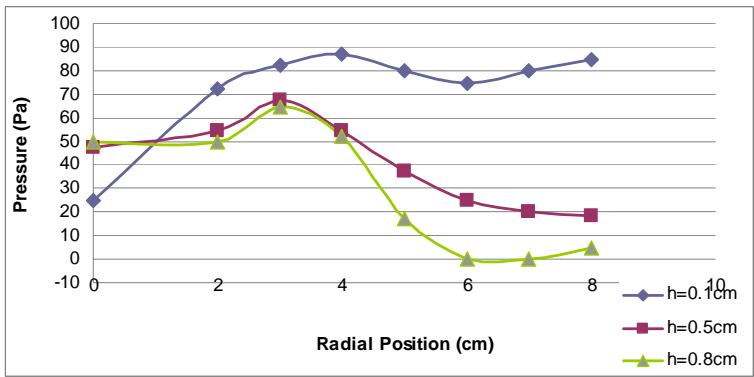

Figure 3: Pressure distribution for different air
gaps

A second experiment was carried out to determine the thrust of the fans. Since the craft was not going to be stationary, the students needed to measure thrust as a function of craft speed. This was achieved by introducing a secondary fan in front of the actual hovercraft fan that could simulate headwinds (see figure 4).

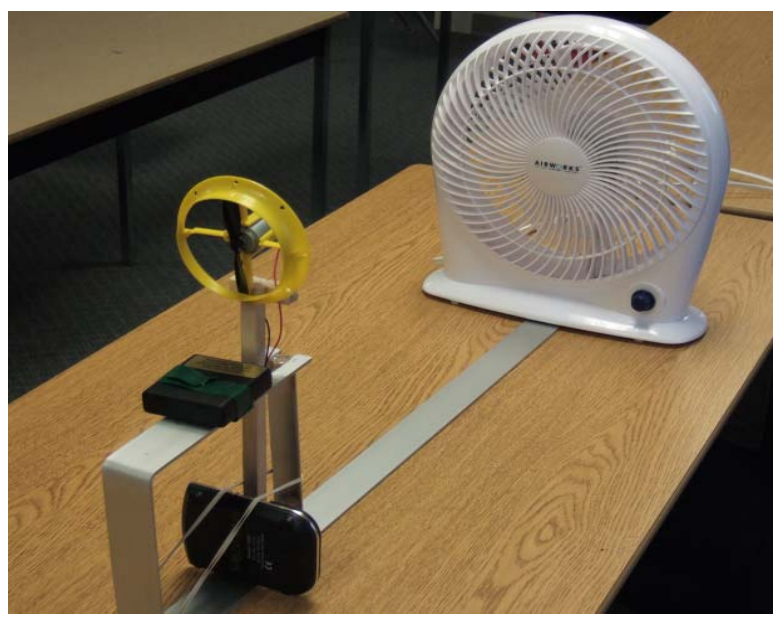

Figure 4: Thrust experiment

By measuring thrust, current supplied to the fan, and wind speeds, the students derived the fan efficiency and thrust as a function of craft speed. A typical plot of thrust vs airspeed is shown in Figure 5.

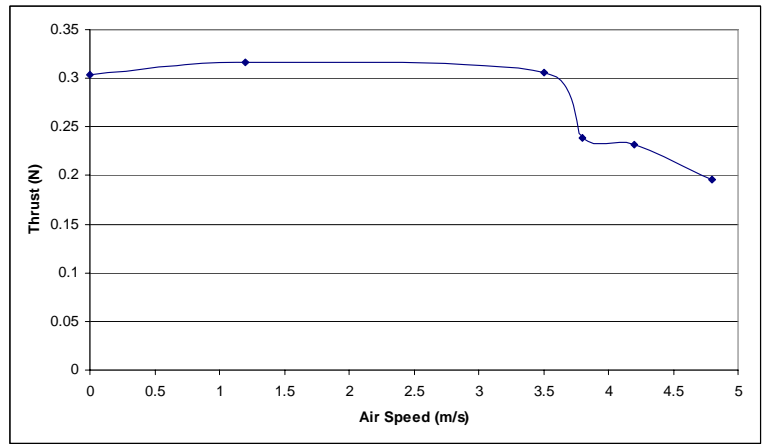

Figure 5: Thrust vs airspeed

\subsection{Power Management}

The fluid experiments also provided the current drawn by the fans for lift and thrust. This data was compared to the capacity of the batteries used in order to predict the operating time of the crafts on a single charge. This information was important to decide whether to have a fast craft with little load or a slow craft with a heavy payload.

\section{Milestone II: Modeling}

Virtual design optimization cycles were performed using the data from the previously carried out experiments. Virtual optimization replaced time consuming hardware based optimization loops. This strategy represents the current trend in industry and teaches the students that only designs based on sound 
engineering models will result in reduced design cost, faster design cycles and overall better products.

\subsection{Balance lift with hovercraft weight and payload}

The structural components (Balsa and paper) were only a fraction of the weight of the batteries and fans. Thus, a good estimate of the final weight of the craft includes all provided building materials plus fans, batteries and control components.

The experiments provided the students with a pressure distribution underneath the Styrofoam plate for different air gaps. This data needed to be normalized to allow predictions of lift for different geometries and numbers of lift fans. A simple numerical integration procedure was used to determine average pressure for a given air gap. In order to include several lift fans, it was assumed that additional fans would not increase pressure, but they would provide proportionally more air flow. Thus, the air gap area can be multiplied by the number of fans used for lift. These assumptions led to the data shown in Figure 6.

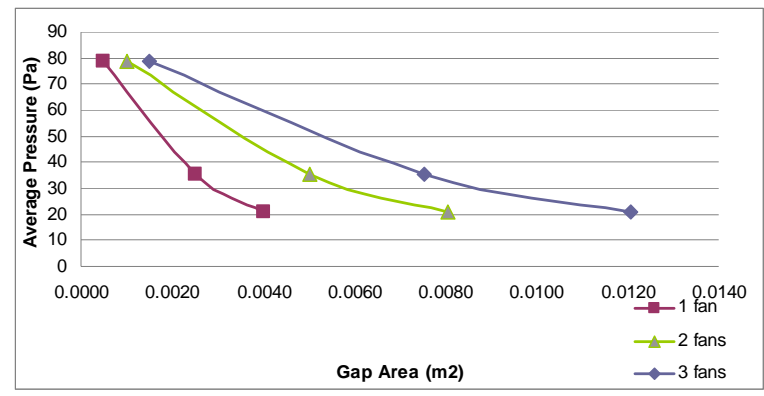

\section{Figure 6: Average pressure for different gap areas and number of lift fans}

In order to determine the optimal size of the craft, the students assumed an air gap that allows safe traveling across minor obstacles along the floor. It was then possible to construct the lift as a function of surface area. In case of a square craft with $2.5 \mathrm{~mm}$ Air Gap and three lift fans, the data in Figure 7 was obtained:

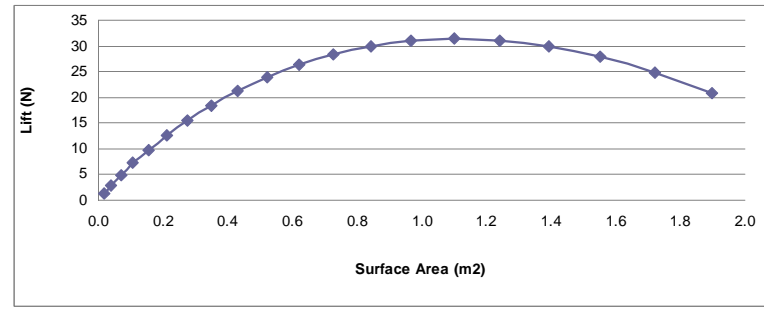

Figure 7: Lift of a square craft with $2.5 \mathrm{~mm}$ air gap and three lift fans
Shapes approaching a circle will provide more lift. However, building such shapes with balsa wood is a greater challenge.

\subsection{Balance drag with thrust}

The thrust is balanced by inertial forces and drag. In our project, a conservative drag coefficient of $c d=0.7$ was assumed in order to determine wind resistance: Assuming a frontal area of $0.0375 \mathrm{~m}^{2}$, the experimental data indicated that the craft has approximately a maximum speed of $4 \mathrm{~m} / \mathrm{s}$ (see Figure 8 )

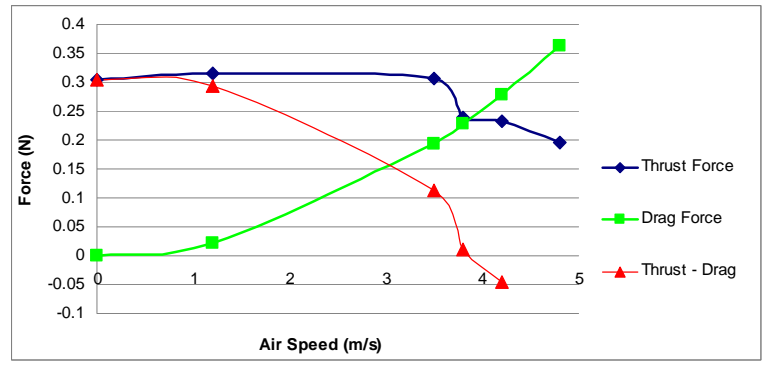

\section{Figure 8: Thrust and Drag vs Air Speed}

However, frontal area is actually a function of size and shape. To determine travel time for a particular geometry and weight combination, the students programmed a simulation of a competition run across the $50 \mathrm{~m}$ gym floor. (see figure90 for a sample run.

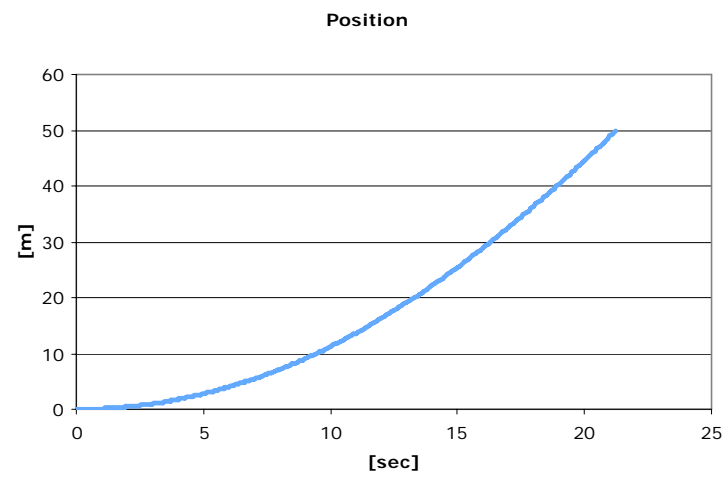

Figure 9: Sample Simulation

\subsection{Structural dimensioning of the craft}

Based on the experimental material properties, the students were asked to design a minimum weight structure using beams, columns and trusses of their choice. The structures were designed for a payload of al least $20 \mathrm{~N}$. The design calculations were required for a parked hovercraft with the lift motors switched off, and a traveling craft with all lift motors on. 
A typical craft would be composed of a number of beams and trusses similar to the ones shown in figure 10.

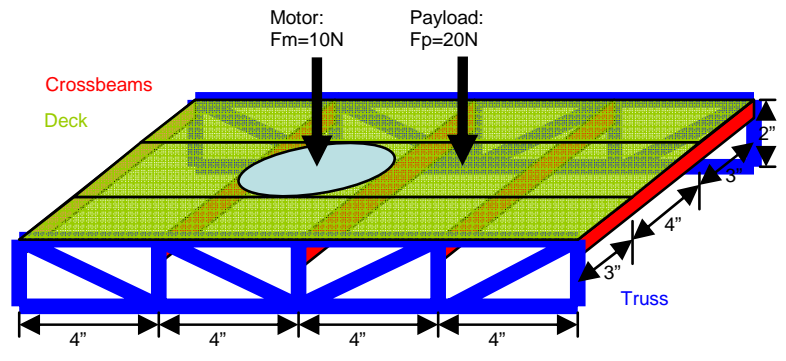

Figure 10: Structure of a typical craft

The load on each of the members was determined for the two load cases, and the dimension for every member was calculated using the experimental data of balsa wood and basic Solid Mechanics analysis techniques

\subsection{Parameter optimization}

The previous sections required the students to pick a shape and a ratio of lift to thrust fans. These parameters were used to calculate lift and thrust. The simulation in section 6.3 could then determine the ratio of payload delivered over time traveled.

In the optimization step, the students were required to vary size, shape and number of fans in order to arrive at an optimum solution.

\section{Milestone III: Manufacturing}

Since most of the optimization was performed virtually using simulations, the manufacturing and testing could be relatively short. The winning team actually performed this step in a single weekend before the competition.

This step involved cutting the balsa boards into the previously designed components of beams, columns and trusses. These components were then glued together with standard white glue. Some additional detailing was required in order to ensure that the joints of the craft would not represent the weakest point of the design (see figure 11)

Paper was used to close the frames and a skirt consisting of plastic bags was attached using two sided tape (see figure 12).

Most teams decided to perform preliminary testing before the competition. This allowed them to address reliability problems such as disintegrating rudders or under inflating skirts.

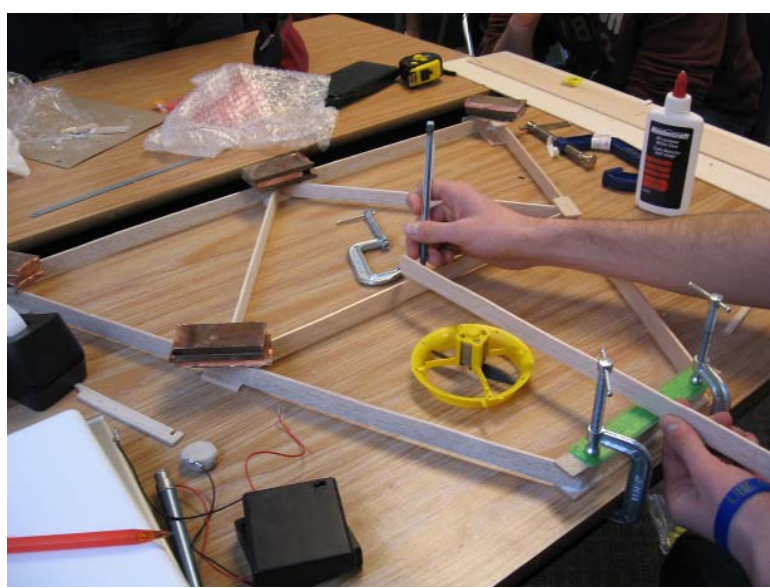

Figure 11: Balsa frame construction

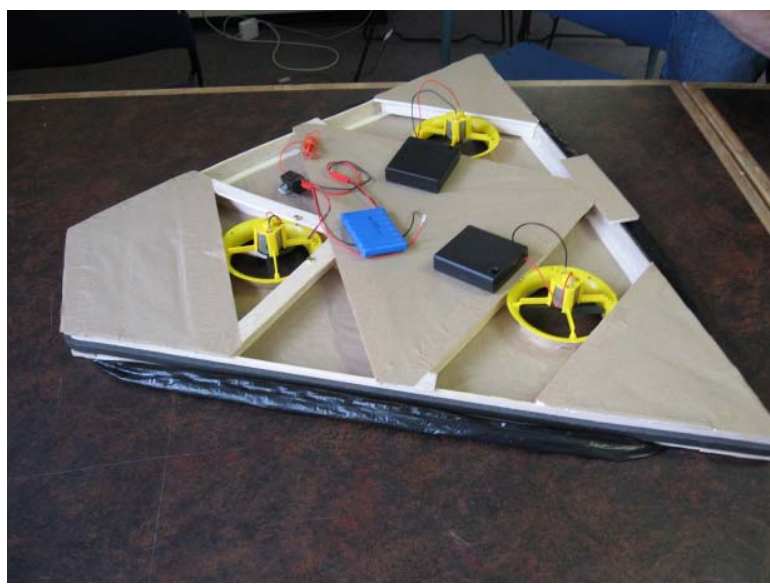

Figure 12: Paper enclosure, skirt, and lift fans

\section{Milestone IV: Competition}

The competition was held on April 112007 in the Gymnasium at UBCO in Kelowna. Nine Teams participated in the competition and eight teams were able to reach the finish lines. The ranking in the competition was determined using three criteria:

\subsection{Races}

The teams needed to finish a straight line course and an obstacle course. There were always two teams racing against one another. However, payload and time was used as the criterion to determine the winner of the races. Figure 13 shows the winning team with a payload of $3.5 \mathrm{~kg}$ at the finish line of the obstacle course. 


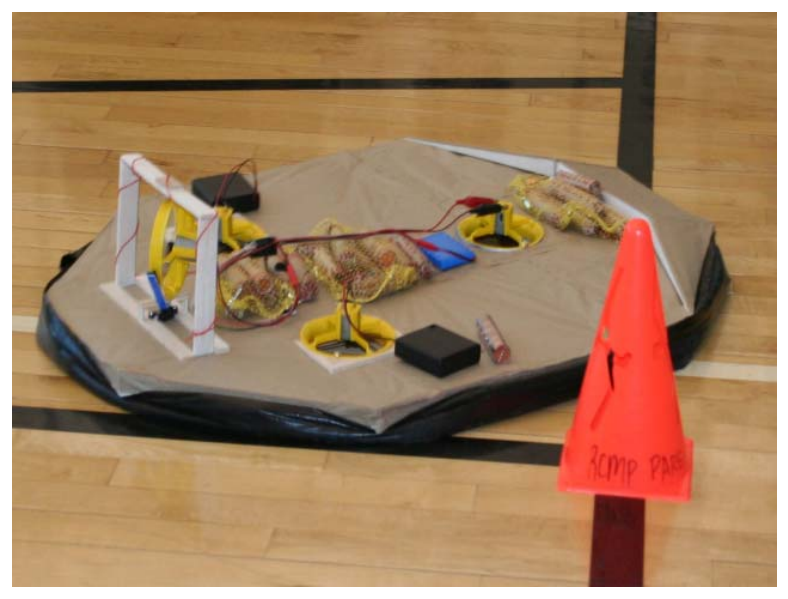

Figure 13: The winning craft at the finish line

\subsection{Structural Strength}

The crafts were subjected to a $20 \mathrm{~N}$ static payload. No craft showed any sign of damage under this load

\subsection{Presentation}

Every team prepared a ten minute oral presentation to judges from the university and industry (see figure 14). The teams were provided with a table to display their craft, posters, and laptop presentations. They were judged according to:

- Technical Content

- Presentation Style

- Handling of Questions

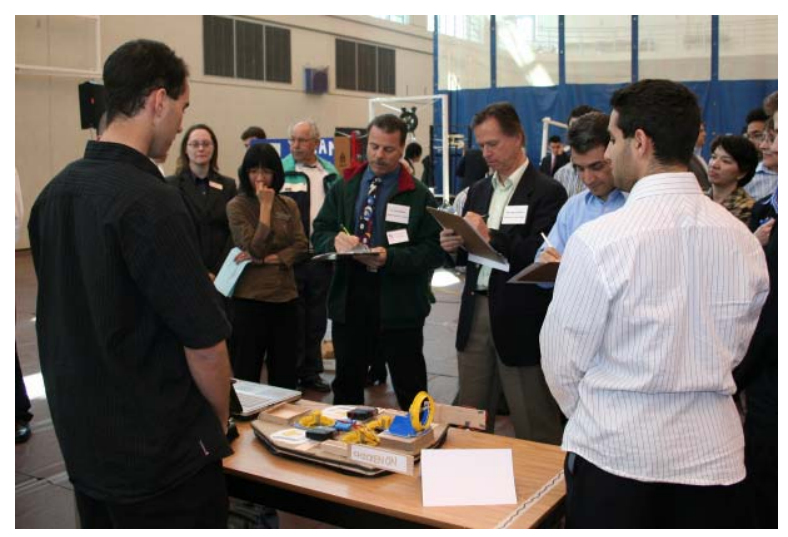

Figure 14: Competition with Judges from Industry and University

\section{Grading}

In addition to the competition (worth $30 \%$ of the project), teams were required to hand in brief reports at every milestone (worth another $30 \%$ of the project) and a final report after the competition (worth the remaining $40 \%$ of the project).

Since the project was part of two courses, the grading between the two courses could differ according to the quality of the work relating to the two courses in the reports.

\section{Summary}

We believe that this project has accomplished three tasks. First, the students were aided in their decision which field of engineering to enter. Secondly, the students experienced the joy of successfully designing a product and they are motivated to stay in Engineering. Thirdly, the students learned to integrate knowledge bases from different fields of Engineering and they were introduced to a real design process with realistic project management issues.

In the future, this project will be improved by changing the focus to a more challenging power management strategy. This could require the teams to deliver the most weight per battery charge. This will include the development of specialized circuitry to measure power consumption as well as distance traveled. This information can then be used by a microcontroller to determine an optimum strategy for delivering thrust and lift.

In the upcoming years, the students will also be required to perform more project management tasks. They will need to develop plans for scheduling, task and resource allocation, budgeting, and documentation.

\section{References}

[1] The University of British Columbia, “2006/2007 Okanagan Calendar”, p. 131

[2] P. Rullkoetter, R. Whitman, R. DeLyser, "Engineering the Future: An Integrated Engineering Design Experience”, 30th ASEE/IEEE Frontiers in Education Conference, October 18 - 21, 2000 Kansas City, MO

[3] SolidWorks, Concord, Massachusetts, USA

[4] "ProBalsa Technical Manual", http://www.diabgroup.com/europe/literature/e_pdf_fil es/man_pdf/Probalsa_Man.pdf 